\title{
La percepción española del levantamiento polaco de 1956
}

\author{
María Dolores Ferrero Blanco \\ Universidad de Huelva
}

The Spanish peception of 1956 Polish raising

\begin{abstract}
RESUMEN ABSTRACT
El levantamiento polaco de 1956 fue una consecuencia de las duras condiciones vividas en el país desde la Segunda Guerra Mundial. Pronto sería seguido y superado por el de Hungría, cuya represión por parte de la URSS hizo que en Polonia se frenara la insurrección: se pactó de cúpula polaca a cúpula soviética.

La información que llegó a España de las embajadas de todas partes del mundo refleja la visión multifacética que recibió el gobierno de Franco. La percepción que el Estado español tuvo del 56 polaco.

PALABRAS CLAVE:

Embajador, Coexistencia, Guerra Fría, Relaciones Internacionales, Política de

The 1956 Polish uprising was a consequence of the hard conditions undergone in the country from the Second World War. It was soon followed and exceeded by the Hungarian uprising. whose repression by the Soviet Union stopped insurrection: the Polish leaders came to an agreement with Soviet leaders. The information received in Spain from the Embassies all over the world shows the multifaceted vision received by the Franco's Government about the influence that these events would have on the bloc policy; the perception that the Spanish State had of the 1956 Polish uprising and its repercussion for the process of peaceful coexistence.
\end{abstract} Bloques.

KEYWORDS:

Ambassador, Coexistence, Cold War, International Relations, Bloc Policy.

\section{ANTECEDENTES DE LA REVUELTA POLACA DE 1956}

Ya durante la década de 1930, y como consecuencia del "crac" de 1929, los países de Europa Centro-Oriental consideraron que era prudente incorporar el Estado a la economía nacional, produciéndose un curioso paralelismo entre las reflexiones keynesianas y las del polaco Kalecki acerca de los peligros del liberalis- 
mo puro y su crisis y llegando éste último a establecer una conexión entre intervención estatal, pleno empleo y el papel del Estado en el plan cuatrienal polaco de 1936'. Tras la Segunda Guerra Mundial, desde los presupuestos estalinistas del Kremlin vencedor en el área de Europa del Este, todas las instituciones, la cultura y la economía polacas fueron subordinadas a las directrices del partido comunista, el PZPR. Pero también en estos años se dio un intento notable de superar esta situación por parte del Movimiento Europeo con la creación de la denominada "Sección de Estudio de los Países del Este», el 17 de agosto de 1949, con representantes de exiliados de varios de estos países. El Movimiento promovió una Conferencia sobre la Europa Central y Oriental en Londres, del 20 al 24 de enero de 1952, en la que se planteó la imposibilidad de un progreso económico y político en una Europa sovietizada.

El espíritu era animar a los cambios precisos para que estos países pudieran modificar sus instituciones en los términos necesarios como para ser capaces de incorporarse al comienzo de lo que sería la construcción europea y que empezaba en la CECA en ese mismo año. Se proponia incluso el traspaso de fondos militares a esa Europa sovietizada, para ayudarla en su transformación, puesto que deberian ser mucho menos necesarios para la defensa en una Europa pacificada. Cuando en 1953 muere Stalin, los exiliados del Este vinculados al Movimiento Europeo creyeron llegado el momento y, más todavía, tras el XX Congreso del PCUS en 1956. Pero los proyectos cayeron en el vacío cuando se vio que la URSS no iba a permitir ningún cambio sustancial en el statu quo posterior a la guerra ${ }^{2}$. Asimismo, EE.UU. demostró sobradamente su apoyo total a los acuerdos de Yalta y su reparto de zonas de influencia en los años posteriores ${ }^{3}$.

En Polonia, en 1955, la sección reformista del partido requirió el regreso de Wladislaw Gomulka, un antiguo afecto a la vieja disidencia de tiempos de Rosa Luxemburgo, que habia crecido ampliamente durante la guerra después del pacto nazi-soviético, cuando Varsovia se levantó contra los alemanes esperando recibir una ayuda rusa que no llegó y que ocasionó tantas muertes de comunistas y de otros partidos de la resistencia. Los sectores reformistas y los deseos de cambio no

1 Mazower, M: La Europa Negra, p. 160, citado por Duafte, A. en Martín de la Guardia, R. y Pérez Sánchez, G. (coords.): La Europa del Este. Del Telón de Acero a la integración en la Unión Europea. Biblioteca Nueva, Madrid, 2002, p. 45.

2 Martín de la Guardia, R.: «El movimiento europeo frente a la división del continente: la Conferencia sobre Europa Central y Orientalı, en Martín de la Guardia, R. y Pérez Sánchez, G. (coords.): La Europa del Este, cit., pp. 47-62.

3 Es suficiente comprobar los telegramas que el Ministerio de Asuntos Exteriores de EE.UU envió para "dar el visto bueno" a la URSS cuando aquella se proponía emprender la invasión a Hungría el 4 de noviembre de 1956. Uno de esos telegramas, enviado al embajador americano en Moscú, Charles Bohlen, el 29 de octubre, decia: «El Gobierno de los EE.UU. no ve a ninguno de los países miembros del bloque soviético como un posible aliado militar y no es de su incumbencia lo que los rusos hagan en Hungria". El 2 de noviembre, otro telegrama enviado a Tito durante su estancia en Brioni, volvía a reiterar la indiferencia de EE.UU.: "El Gobierno de los EE.UU. no contempla favorablemente a esos gobiernos que están en relaciones poco amistosas con la URSS". Jrushchov y Tito contestaron que en uno o dos días resolverían el asunto. Pongrátz, G.: Corvin circle, 1956. Ed. Szivárany, Chicago, 1983, p. 14. 
eran exclusivos de Polonia, sino compartidos por otros países del área, en especial por Hungría. Creían que las causas del malestar eran sobre todo dos: una, el sentimiento de humillación patriótica por la política dictada desde la URSS y la otra, la miseria del nivel de vida y la decepción ante las medidas con que la URSS trataba de paliar la crisis económica cotidiana y que no tenian éxito alguno.

Muestras de esa situación aparecen en el testimonio del embajador de España en Finlandia, Fulgencio Vidal y Saura, que estaba al corriente por el diplomático finés Shelman, secretario a su vez de la embajada de Finlandia en Varsovia ${ }^{4}$. Según las observaciones del matrimonio Shelman, la URSS utilizaba continuamente estrategias sin éxito para congraciarse con la población polaca, como el nombramiento de un jefe del Ejército que aunque había llegado de Rusia, era de origen polaco, Rokossovski, o la construcción de un rascacielos espectacular para sede cultural y formativa de la juventud. Estas medidas eran tomadas como conciliadoras, pero no parecían satisfacer suficientemente y los polacos mostraban su rechazo prefiriendo "lo occidental» hasta el punto de apoyar la concesión de cualquier clase de méritos y honores a los extranjeros, incluso por delante de los nacionales, con tal de molestar a la URSS 5 .

La prelación característica de la Unión Soviétiva por las industrias básicas y el descuido de las ligeras en la economía planificada de su esquema económico, se reflejaba también en la escasez de abastecimientos, aún siendo de necesidad primaria. Mientras había, en ocasiones, abundancia de frutas y verduras, incluso alimentos en general, escaseaban las telas tanto en pieza como en vestidos confeccionados. Por ello, las oportunidades de que los extranjeros se beneficiaran y de que la población especulara eran muy numerosas. La necesidad cotidiana impulsaba a recurrir al mercado negro siempre que era posible, pese a que estaba castigado con la pena de muerte y que los registros de aduanas eran preceptivos a la entrada y salida del pais ${ }^{6}$.

En el orden espiritual, sin embargo, observadores externos como los Shelman admiraban la tolerancia religiosa que consideraban muy superior a la de cual-

4 El matrimonio Shelman trabó una gran amistad con Vidal y Saura y fueron para él una fuente de información muy valiosa sus impresiones mientras residieron en Polonia. La esposa de Sheiman, española de origen, tras su estancia en Polonia llegó a Finlandia a dirigir una casa de modas por lo que formaba parte de su actividad la observación del atuendo y accesorios de la población y de otros aspectos de la vida cotidiana que comenta profusamente. Informe del embajador de España en Finlandia Fulgencio Vidal y Saura. AMAEX, R-4452-45.

5 Un caso conocido fue el de las protestas en el prestigioso Concurso Chopin porque le negaron el primer premio a un francés, al que la multitud sacó a hombros desafiando al jurado oficial. Idem, AMAEX, R-4452-45.

6 Sin embargo, era de todos sabido que se podía relajar la investigación del equipaje si se invitaba al funcionario responsable a unas copas o se le hacía un regalo de algún producto que alli escaseara. Habida cuenta de que los polacos consideraban todo lo soviético como una "porquería" - en sus propias palabras-, y la pobreza propiciaba que se pudieran adquirir objetos antiguos, como plata o alfombras muy valiosas, a bajísimo precio si uno se aprovecha de la miseria reinante, los vendedores del mercado negro pululaban incesantemente por las embajadas. Hay que tener en cuenta que en 1955 se cambiaban 80 zlotys por 1 dólar y costaba el viaje en avión de ida y vuelta Helsinki-Varsovia, 12 dólares. El nivel de vida para los extranjeros era realmente barato. Idem, AMAEX, R-4452-45. 
quier otro país de la Europa Centro-Oriental. En su opinión, era evidente que la población no se había convertido al comunismo y las iglesias católicas se llenaban los domingos a las horas de las misas, incluso formando colas en la calle cuando no podían entrar. Los sacerdotes se desplazaban sin problema alguno por la ciudad con sus sotanas y todo tipo de signos externos religiosos, y los observadores sostuvieron en aquellos días que "el culto católico se desarrollaba en absoluta libertad y sin prevenciones ni represiones"?.

Estas apreciaciones coinciden en todo con la documentación oficial de que se dispone, especialmente con los informes de Fernando María Castiella, a la sazón embajador de España en la Santa Sede. Él menciona frecuentemente la relación del Vaticano con Polonia, en especial en una Carta Pastoral de los Obispos polacos tras la celebración de una Conferencia Episcopal, en que aludía, en septiembre de 1955, al esplendor de las celebraciones del Año Mariano. Aunque lamenta que la prensa no se hace eco de ello, dice que «los polacos llegan en multitud a los santuarios católicos y se acercan a los confesionarios, a la Santa Misa y a los Retiros Cuaresmales, cada año en mayor número" ${ }^{8}$. A este testimonio se añaden las felicitaciones del Santo Padre por el aniversario de la victoria de Yasna Gora, de católicos contra protestantes ${ }^{9}$. No obstante, y aún con esas manifestaciones públicas de religiosidad, evidentemente permitidas por las autoridades, también se menciona en la Carta Pastoral de los Obispos, en forma aparentemente contradictoria, que "la Iglesia Católica debe superar dificultades frente al comunismo y que el pueblo polaco resiste la persecución aumentando su fe" ${ }^{10}$.

\section{LA REVUELTA POLACA DE 1956}

Como es sabido, después de que Jrushchov proclamara los cambios modernizadores y nacionalistas del XX Congreso del PCUS y se produjera su reconciliación con Tito, los países del denominado bloque del Este creyeron llegado el momento de las "vías nacionales al socialismo" - según el término acuñado por Yugoslavia- y Polonia y Hungría fueron especialmente sensibles a la necesidad de llevar a la práctica esa nueva apertura. El movimiento revolucionario de Polonia, paralelo al de Hungría, tuvo su inicio en las protestas de los obreros polacos de Poznan (Posen) en Polonia, por causa de los bajos salarios y las dificultades generalizadas de supenvivencia. En Polonia, el germen provenía de un grupo refor-

\footnotetext{
7 AMAEX, R-4452-45

- Carta Pastoral Polaca. Despacho 19 de 16 de enero de 1956 de Femando María Castiella. AMAEX, $\mathrm{R}-4452-13$.

- Se refiere al 300 aniversario de la defensa del Santuario polaco de Czestochowa donde venció el rey Casimiro, católito, a los protestantes del rey Carlos Gustavo de Suecia. Despacho 81 de 1 de marzo de 1956 de Fernando María de Castiella. AMAEX, R-4452-13.

10 Este comentario procede de la Carta Pastoral citada: AMAEX, R-4452-13. No obstante, este es un tema a estudiar más profundamente (la realidad práctica del acuerdo de convivencia entre el Gobierno polaco y la Iglesia católica) y forma parte del actual proyecto de investigación que se está acometiendo.
} 
mista del partido, el Pulawianie, que emprendió la elaboración de un programa de reformas sociales que de inmediato fue secundado por la juventud y los intelectuales. La oposición a este proyecto, el Natolinczycy, apoyaba los métodos de Moscú y requirió su ayuda cuando los anteriores tomaron las calles manifestándose en pro de sus peticiones.

En los días 28 y 29 de junio los trabajadores salieron a las calles de Varsovia comenzando por demandar mejoras económicas, pero ampliando sus reivindicaciones muy poco después con proclamas patrióticas y antigubernamentales. Llegaron a la cárcel, liberaron a presos, robaron armas y fueron reprimidos por los tanques que les causaron casi un centenar de muertos y cerca de un millar de heridos. La actitud del Gobierno exacerbó el odio al régimen y pronto empezaron a funcionar los "consejos" en las fábricas e implantarse nuevos planes de estudios sin reconocimiento oficial. Después de las huelgas y manifestaciones de junio y de la represión consiguiente, cambia la temática de los informes de algunos diplomáticos españoles. Fulgencio Vidal y Saura, de Finlandia, o Ramón Sedó Gómez, de Berna, criticaron con permanente rotundidad la prensa que comparaba la represión polaca contra los obreros metalúrgicos con la ejercida en España, precisamente en ese tiempo, en el mismo sector ${ }^{11}$.

De modo paralelo, en Hungría, donde la situación provocada por el régimen proestalinista de Mátyás Rákosi era insostenible, se estaba observando la actitud de Polonia desde junio de 1956 en que se había nombrado a Gomulka secretario del Partido Comunista Polaco, desplazando asi a los estalinistas. Con el deseo de conseguir algo similar, los estudiantes de Budapest, pertenecientes al Círculo Petöfi, comenzaron a decir «ihagámoslo a la manera polaca!» e, indiscutiblemente, el levantamiento húngaro fue iniciado como un acto de solidaridad con Polonia $^{12}$. Después, sin embargo, la tragedia de la represión húngara evitaria la de Polonia, que obtendría logros parciales pactados por las cúpulas polaco-soviéticas ante la imposibilidad del PCUS de atender dos frentes abiertos simultáneamente y ante las especiales circunstancias polacas de vecindad geográfica con la URSS.

Lo que habia provocado en Hungria la admiración por Gomulka había sido el apoyo en bloque que le prestó la cúpula polaca cuando Jrushchov voló a Varsovia

Ir Son los «cuidadores de la imagen de España» que aparecen con frecuencia y que no admiten que en su país de origen hay una dictadura y que existe la represión igual que en los países del bloque del Este. En este caso concreto, Fulgencio Vidal y Saura critica un artículo que ha conocido del Journal de Geneve en el que se compara la represión comunista polaca con la franquista ante las protestas de los obreros metalúrgicos y añade que «ha causado gran extrañeza en Helsinki». Asimismo, el embajador de España en Berna, Ramón Sedó Gómez, denuncia las declaraciones del Secretario de la Federación Internacional de Obreros Metalúrgicos, Adolf Graedel, protestando por «la cruel represión del movimiento obrero metalúrgico en Posen y en el Norte de España». Despacho 176 de Fulgencio Vidal y Saura, Encargado de Negocios de España en Finlandia, de 2 de julio de 1956; Despacho 730 de Ramón Sedó Gómez, Encargado de Negocios de España en Berna, de 3 de julio de 1956. AMAEX, R-4470-14.

12 Para mayor información acerca de la revolución húngara ver FERRERO BLANCO, M. D.: La revolución húngara de 1956. El despertar democrático de Europa del Este. Coedición Universidad de Huelva-Embajada de la República de Hungría en España-Instituto siglo XX-siglo XXI de Budapest. Universidad de Huelva, 2002. 
para atajar lo que desde Moscú se había considerado un acto de rebeldía e, incluso, las tropas soviéticas se habían movilizado ${ }^{13}$. Pero en Polonia la decisión del nuevo gobierno de no pretender cambios en los verdaderos cimientos del régimen y de seguir perteneciendo al Pacto de Varsovia, alejó el peligro de un enfrentamiento entre Polonia y la URSS. Así, mientras en Hungría estallaba un movimiento popular irrefrenable de consecuencias dramáticas, en Polonia Jrushchov y Gomulka llegaron a acuerdos que abortaron la rebelión.

La versión soviética de los hechos tanto húngaros, como polacos, fue conocida en Occidente sobre todo por las declaraciones del 24 de octubre de Chepilov y por la del primer diario soviético, Pravda, en su editorial del 4 de noviembre. Ese día, el de la entrada masiva de los tanques en Budapest, Chepilov hizo la primera declaración oficial de un miembro del gobierno soviético. Afirmó que la situación húngara era mucho más complicada que la polaca y admitió que había muchas razones para el levantamiento de Hungría, pero que se habían aprovechado de ello los elementos contrarrevolucionarios y que el gobierno húngaro se había visto obligado a pedir ayuda a la Unión Soviética ${ }^{14 .}$

Desde el punto de vista estrictamente político, las revoluciones húngara y polaca de 1956 se compararon continuamente desde entonces. Uno de los más notables juicios acerca de ambos levantamientos es el de Nahuel Moreno, polítólogo trotskista fallecido en 1986 sin conocer la caída de los sistemas del «socialismo real". Este autor, frente a una mayoría que había calificado estos movimientos de «luxenburguistas», los consideró de inspiración «trotskista», con tres notas sobresalientes en su desarrollo:

- En primer lugar, su analogía con las fases de la revolución rusa. En su opinión, los levantamientos húngaro y polaco fueron «revoluciones completamente diferentes de las anteriores y absolutamente necesarias para derrocar a la burocracia y retomar la verdadera marcha hacia el socialismo: allí, las masas, aplicando el programa trotskista ortodoxo, murieron por decenas de miles combatiendo por la expulsión del Ejército Rojo y hubo una similitud de los 'comités de fábrica' de Polonia y los 'consejos obreros' de Hungría con los primeros soviets rusos de 1905". Igualmente insiste en la similitud que hubo

13 Wladyslaw Gomulka había sido un comunista tradicional, secretario del partido hasta que en 1948 fue condenado por «desviaciones nacionalistas", lo que después se conocería en todo el área como «titoísmo". Fue liberado en 1955 y empezó a tener un gran prestigio entre medios populares e intelectuales. Cuando estaba en camino la nacionalización de la industria, en junio de 1956, se dieron importantes protestas en los astilleros de Poznan y el movimiento terminó con la destitución del estalinista Bierut y el nombramiento de Gomulka como Primer Secretario del Partido en octubre de 1956. Fue considerado la representación de la "vía polaca al socialismo», aunque más tarde, tras los hechos de Hungria, Gomulka rebajaría sus planteamientos. En cualquier caso ya no se volvió al estalinismo puro en Polonia: se habia logrado que terminara la colectivización agraria forzosa y el $75 \%$ de las tierras pasó a manos privadas. Además, se iniciaba una convivencia -aunque dificil y tensa- con la Iglesia Católica.

14 Este es un argumento empleado con profusión y absolutamente falso. El Gobiemo de Nagy jamás pidió ayuda a la URSS para ninguna intervención. La mención de este hecho, en los medios de oposición, siempre confunde a Nagy con Gerö, que fue el que realizó la petición. 
entre las insurrecciones húngara y polaca y el levantamiento espontáneo de Rusia de febrero de $1917^{15}$.

- En segundo lugar, sostiene que "el imperialismo ayudó al Kremlin dando el visto bueno a la represión» y, como prueba de esta afirmación, alude a una noticia de la agencia United Press publicada en La Prensa de Buenos Aires, que decía: «El gobierno norteamericano informó a Yugoslvia de que aunque EE.UU. es partidario de la independencia de los paises satélites de Europa Oriental, se opone a la aparición de nuevos gobiernos hostiles a Rusia»"

- En tercer lugar, por último, el carácter de ambas insurrecciones, húngara y polaca, de "revoluciones" y no de "contrarrevoluciones con deseos de vuelta al capitalismo", lo que ya es universalmente admitido entre los estudiosos de ambos procesos: en ninguno de los dos casos, ni polaco ni húngaro, se planteó una vuelta atrás en las reformas agrarias realizadas desde 1945 y en ningún momento fue un objetivo entregar el poder a las viejas oligarquias. Sobre este aspecto, el autor se remite a un artículo aparecido en la prensa francesa en la que se dijo literalmente: «El error más grande en estas crisis sería confundir a Moscú con el comunismo (...) La convulsión polaca, lejos de representar síntomas de decadencia del comunismo, lo que desea es reencontrar las fuentes, superar los obstáculos y despertar el espiritu de revuelta" 17.

Todas estas matizaciones y observaciones acerca de qué ideólogo fue más seguido o admirado por los revolucionarios húngaros o polacos no interesaron en absoluto a los diplomáticos españoles. Nuestros embajadores e informadores no se detuvieron en matizaciones de esta índole y su lectura fue grosso modo de "revueltas que se oponian al comunismo", sin distinguir entre modelo soviético y las

15 MoReno, N.: Escritos sobre revolución política. http://www.geocities.com/obreros.geo. Edición electrónica. Diciembre, 2001, p. 2.

${ }^{16}$ Esta afirmación se refiere a la actitud que se había mantenido en EE.UU. desde que se apreció la magnitud de las revoluciones, sobre todo en el caso de Hungria. Cuando los húngaros fueron atacados por los tanques rusos y aún confiaban en la ayuda del "Occidente libre", el gobiemo americano demostró en la práctica que reconocía "el derecho" de la URSS sobre su área de influencia. Ya en un discurso de Foster Dulles, por indicación de Eisenhower, se había dicho: «Los paises de Europa Oriental que consigan su libertad no constituirán una amenaza par la seguridad de la URSS porque los EE.UU. no los considerará como aliados militares potenciales". Esa idea se concretó posteriormente en dos telegramas enviados por el Ministerio de Asuntos Exteriores americano, uno a su embajador en Moscú, Charles Bohlen, el 29 de octubre de 1956, y otro a Tito, el 2 de noviembre del mismo año. En el primero decia textualmente: «El gobierno de los EE.UU. no ve a ninguno de los países miembros del bloque soviético como un posible aliado militar y no es de su incumbencia lo que los rusos hagan en Hungria". El texto del segundo era: «El gobierno de los EE.UU. no contempla favorablemente a esos gobiernos que están en relaciones poco amistosas con la URSS". La luz verde a la intervención rusa en Hungria se encendió de inmediato y Jrushchov y Tito contestaron a EE.UU. que en uno o dos dias “resolverian el asunto". PONGRÁTZ, G.: Corvin circle, 1956. Ed. Szivárany, Chicago, 1983, p. 14.

17 Le Figaro, 23 de octubre de 1956. En efecto, al margen de que se unieran en las protestas todos los descontentos y los había de muchos sectores, el planteamiento oficial, gubernamental, nunca fue un regreso al capitalismo sino una reforma del socialismo. Un "socialismo democrático", como le liamaron concretamente en Hungría. 
reformas del socialismo que se estaban buscando. Sin embargo, es justo reconocerles que tuvieron una información bastante precisa de las posibilidades y dificultades que entrañaba la oposición a la URSS desde una visión evidentemente impregnada de su espírtu anticomunista, a través del que juzgaban y valoraban todos los enfrentamientos que para la mayoría de ellos eran sencillamente «disputas entre comunistas ${ }^{18}$.

\section{LAS VERSIONES DE LOS DIPLOMÁTICOS ESPAÑOLES SOBRE EL LEVANTAMIENTO POLACO}

Las versiones o interpretaciones de los diplomáticos españoles en los diferentes países europeos acerca del pronóstico o futuro de la crisis polaca fueron de muy diversa índole. Una primera clasificación podría agruparlos en dos sectores: los escépticos y los optimistas. Posteriormente habria que puntualizar que existian escépticos por dos causas diferentes: una de ellas, por no creer en la tolerancia de la URSS para permitir ciertos cambios en Polonia y otra, por considerar que si era posible que la URSS tolerara un cambio, pero que eso sería negativo para Occidente porque reforzaria a los comunistas. En cualquier caso, valoraban las posibles consecuencias del levantamiento negativamente.

El otro sector, los que si confiaban en una posible mejora de la situación, también fueron dos grupos diferentes: los partidarios de que la alternativa estaba en la oposición exiliada en Londres (desde la posguerra mundial) y los que creyeron en la transformación desde los reformadores del interior. Sin embargo, antes de exponer estos puntos de vista encontrados, y con el objeto de conocer ordenadamente el desarrollo de los hechos, atenderemos al informe del embajador de España en Bonn, Antonio María de Aguirre. Él es siempre la fuente minuciosa por excelencia de Europa Centro-Oriental y nos describe detalladamente el proceso.

\subsection{El testimonio descriptivo del proceso: Antonio María de Aguirre, embajador de España en Bonn}

Antonio María de Aguirre es uno de los más precisos informantes de los diplomáticos españoles en el extranjero. Siguiendo su relato, el desarrollo de los hechos habría sido como sigue:

\section{El inicio de los disturbios}

Tras los primeros desórdenes obreros ocurridos en Poznan y hecha la convocatoria de huelga, parecía que había vuelto una calma relativa hasta que Gomulka

18 Informe de José de Erice. AMAEX, R-4465-89. 
pronunció un discurso acerca de la lamentable situación polaca ante unas doscientas cincuenta mil personas en Varsovia. Quienes lo escucharon fueron hacia la embajada soviética profiriendo gritos antirrusos y en la noche del 24 al 25, Varsovia se llenó de patrullas armadas. El día 25 el Partido Comunista Polaco condenó toda tendencia nacionalista y todo antisemitismo, aunque dijo aprobar la política iniciada por Gomulka. Asimismo, por radio se difundió que debía continuar la alianza indefectible con la URSS porque era la única garantía de la frontera Oder-Neisse ${ }^{19}$.

La huelga sorprendió inicialmente a las autoridades porque, como ocurriría meses después en Hungría, el Gobierno había comenzado aceptando las reivindicaciones de los sublevados, aunque más tarde se retractaría. En el caso polaco, el Comité Central se habia reunido en sesión extraordinaria el miércoles 27 por la noche y había terminado aprobando las peticiones básicas de los obreros, pero era demasiado tarde ya puesto que la huelga estaba convocada para el jueves 28 . Desde esa mañana, el clima se fue caldeando y los obreros se manifestaron cantando por las calles de Poznan con ocasión de la apertura de las fábricas metalúrgicas Stalin. Se unieron a los de otras fábricas y marcharon coreando gritos de "pan, libertad y democracia". Los obreros amotinados -se hablaba de unos 300.000-, según Aguirre, trataron de asaltar el cuartel de la policía política, iban armados de metralletas $y$, ante su ataque, las autoridades contestaron al fuego que procedía de la multitud. Se suspendió la circulación de todos los transportes públicos y las comunicaciones telefónicas con el exterior, hasta que a las cinco de la tarde hubo que cerrar la Feria Internacional que se estaba celebrando y que habia convocado a un gran número de extranjeros.

Al día siguiente, el 29 por la noche, el presidente del Consejo Polaco, Zirankievicz, se dirigió a los ciudadanos por radio y calificó los incidentes de "verdadera insurrección armada», cuya autoría atribuía a "manejos de agentes extranjeros y a organizaciones reaccionarias ilegales" ${ }^{20}$. El resultado, según las fuentes oficiales, fue de 38 muertos y 270 heridos, pero desde un principio nadie creyó esas cifras. Dice el propio Aguirre: «Según hombres de negocios de Alemania Occidental que volvieron de allí después de haber presenciado los hechos, el número de muertos y heridos debía ser mayor, dada la envergadura de la sublevación».

19 La alusión al antisemitismo responde a una concepción tradicional que asocia a los judíos con comunistas, dado que la mayor oposición antinazi durante la guerra fueron los comunistas y, ciertamente, muchos de ellos eran judios. Ese hecho se aprovechará después con frecuencia por los dirigentes comunistas para acusar de antisemitas a los que protestan contra la URSS. Respecto a la frontera Oder-Neisse, será un tema recurrente y singular de Polonia porque siempre temerá que si la URSS la condena, puede perder los territorios de esa franja que fue «donada» tras la guerra a cambio de un desplazamiento de la frontera occidental rusa sobre Polonia. Despacho 618 de 26 de octubre de 1956. AMAEX, R-4465-86.

20 Es el efecto de las influencias de EE.UU en el exterior y de los fascistas o pro-nazis, sucesores de los de la Segunda Guerra Mundial, en el interior. Es un recurso repetidamente utilizado por los gobiemos pro-soviéticos y por la propia URSS cuando se daba cualquier protesta en su entorno económico o político. No obstante, existe también la posibilidad de que tuviera noticias de los esfuerzos de los exiliados de Londres que, según el testimonio de Andres, intervinieron intensamente. 


\section{Las causas y las reivindicaciones de los obreros}

Las motivaciones del descontento habian sido, en primer lugar de orden económico, pero, en segundo lugar, político, por el gran desengaño de la política rusa. Las peticiones podrian resumirse en tres: laboral, por la mejora de salarios; política, con la demanda de libertades democráticas; nacionalista, por la salida soviética de Polonia. Hubo comparaciones con los sucesos del 17 de junio de 1953 en la zona soviética de Alemania, pero lo de Polonia se evaluó como mucho más grave por las siguientes razones:

- En Polonia eran grandes masas de trabajadores las que se manifestaban contra el gobierno prosoviético de su país y no jóvenes inexpertos, como la mayoría de los que se manifestaron en 1953 en Alemania del Este o en 1956 en Hungría.

- Las masas iban armadas hasta con ametralladoras.

- En Alemania se podía contar con la posible huida a la zona occidental, mientras que en Polonia estarían atrapados. No tenían posibilidad de escape.

- Fue la policía política quien disparó contra los manifestantes. No lo hicieron ni la policía del Estado, ni el ejército²1.

\section{El tema fronterizo}

Aguirre analiza también la delicada situación existente en el entorno polaco del momento respecto a dos cuestiones fundamentales: la frontera ruso polaca y las iniciativas acerca de la posible unificación alemana. La primera, el tema fronterizo Oder-Neisse, era sobre el desplazamiento de la frontera impuesto a Polonia por la URSS en los acuerdos posbélicos. El embajador apunta que la proximidad territorial impedía a Polonia poder mantener una posición de enfrentamiento con la URSS, como había podido sostener, por ejemplo, Tito en Yugoslavia ${ }^{22}$.

Por lo que se refiere al tema de la reunificación, en septiembre Alemania Federal había dirigido una propuesta a Moscú de convocar elecciones en Alemania, pero Moscú contestó que estimaba que en plena revuelta polaca «no existían circunstancias propicias para la celebración de elecciones generales en toda Alemania, además de que ese tema lo deberían hablar con Pankow» ${ }^{23}$. Alemania Federal seguía llamando a la Alemania del Este "zona de ocupación soviética" y no

21 Aguirre, en un primer informe, dice que sólo han disparado al aire, pero aquí ya admite que han disparado a los obreros. Despacho 381 de 6 de julio de 1956.

22 Desde el final de la guerra, la URSS había desplazado su frontera occidental hasta incorporarse parte de Polonia y había querido compensar a Polonia con otro desplazamiento de la frontera polaca hacia Alemania: la línea Oder-Neisse, que fue ya para siempre objeto de constantes disputas polaco-alemanas.

${ }^{23}$ Despacho 609 de Antonio María Aguirre de 24 de octubre de 1956. AMAEX, R-4465-85. 
la había tratado nunca como un Estado soberano, sino como a una colonia de la URSS. Pero, sin percibirlo, el propio Adenauer aceleró la formalización del Estado alemán del Este, con su rápida integración en la alianza occidental y su entrada en la OTAN. Incluso Adenauer rechazó dos ofertas de unificación de Moscú, en 1952 y en 1955 y, pese a que la primera debía ser sólo propaganda soviética, la segunda, muerto ya Stalin y con tantas luchas de poder en el Kremlin en estos años, posiblemente hubiera tenido visos de realidad futura. Esta segunda propuesta, la de Beria - asesinado poco después, según se dijo por la «traición alemana" - parece que fue la única opción que había sido contemplada por la URSS y planteaba una "venta" de la RDA; es decir, una dejación por parte de Moscú de sus intereses en la RDA, a cambio de algo que no llegó a hacerse público. Era la propuesta de un acuerdo global entre ambas potencias, que, probablemente, ni llegó al Departamento de Estado americano porque antes debió ser abortada en el propio Kremlin ${ }^{24}$.

\section{Las consecuencias político-económicas de la revuelta}

El primer resultado político de la crisis polaca fue la incorporación de Wladislaw Gomulka al Comité Central del Partido Obrero Unificado de Polonia. También fueron admitidos Marian Spychalski, Ignacio Loga-Sowinski y Zenón Kliszo, todos ellos muy populares y anteriormente rechazados por heterodoxos. El 19 de octubre de 1956 se reunió en sesión plenaria el Comité Central del Partido esperando la llegada a Varsovia de Jrushchov, Mikoyán, Kaganóvic y Mólotov. La presencia de Jrushchov y Mólotov en esa delegación, símbolos del «blando" y el "duro" con respecto al tema de las "vias nacionales", era indicativa de la importancia que se había dado en el Kremlin al tema polaco, pues creían que debian estar presentes para la decisión todas las tendencias del PCUS. No hay duda de que la delegación rusa había ido a Polonia por temor a que las autoridades polacas adoptaran medidas desestalinizadoras con demasiada rapidez, que podrían poner en aprietos al mariscal Rokosowski, prosoviético y jefe del ejército polaco. En la concepción rusa, mientras estuviera en su puesto Rokosowski, no habría motivos de preocupación, pero sí comenzarían en cuanto aquel tuviera una posición débil.

En esa sesión, Gomulka tuvo una actitud segura y respaldada por todo el Comité e hizo algunas afirmaciones sorprendentes, como que era absurdo hablar de provocación por parte de los obreros y que las manifestaciones eran justificadas. Seguidamente planteó su posición, también tajantemente y habló de la necesidad de descentralización económica; abandono de las colectivizaciones forzosas en el campo; ayudas individuales a campesinos y artesanos; desarrollo de las industrias de consumo; mejoras en la situación laboral de las minas;

24 HélLer, A. y Feher, F.: De Yalta a la «Glasnost». Ed. Pablo Iglesias, Madrid, 1992. pp. 124-137. 
mayor independencia de los sindicatos, y mayor representatividad del Parlamento ${ }^{25}$.

El dia 21 Gomulka pronunció un discurso en el que manifestó con toda claridad que tenía la intención de acelerar la liberalización del régimen y de tener un espíritu de mayor independencia para con el exterior. Los telegramas de adhesión empezaron a llegar de forma ininterrumpida, incluso reclamando sanciones para los antiguos dirigentes. Una muestra simbólica del resurgir del sentimiento nacional se dio en el rápido acuerdo del Consejo Municipal de Stalingrado para darle a la ciudad su antiguo nombre de Katowice.

\section{El viraje tras el levantamiento húngaro del 23 de octubre: el final de la rebelión}

Tal vez todos estos cambios, apresurados y que parecian tener la intención de seguir por tiempo indeterminado hubieran sufrido un freno de Moscú. Pero, a los dos días, el 23 de octubre, tuvo lugar en Budapest la manifestación que abrió la crisis húngara y esa misma noche hubo una masacre frente al edificio de la radio nacional de la capital. En ese momento Moscú necesitó ganarse a Polonia y no tener dos frentes abiertos. Desde el 23 de octubre Polonia se salvó porque se había sublevado también Hungría. Todo el interés de la URSS desde ese momento fue pactar: ya sólo se hablaba de negociación.

Al mes siguiente, en noviembre, se convocó en Moscú a una delegación gubernamental polaca, presidida por Gomulka, para negociar con los dirigentes soviéticos. En ella iban Cyrankiewicz, primer ministro; Zavalski, presidente del Consejo de Estado, y un representante de la comisión económica. Gomulka dijo en ese acto que las negociaciones deberían entablarse dentro del respeto a la soberanía de Polonia, a la no injerencia y a la igualdad de derechos. También hizo alusión a la línea Oder-Neisse, diciendo que estaba garantizada por la alianza con la URSS.

La delegación fue recibida por Voroshilov, Bulganin y Jrushchov y se suponía que se tratarían temas políticos, militares y económicos. Pero a los tres días, el 18 de noviembre, cuando terminó la reunión y se publicó un comunicado, la conclusión era la necesidad de permanencia de las tropas soviéticas en Polonia, aunque con unos acuerdos especiales ruso-polacos que se deberian establecer. Aguirre concluye su informe lamentando que Gomulka no hubiera sido capaz de conseguir la retirada de las tropas, que desde ese momento se quedarían aún más legitimadas por el acuerdo firmado ${ }^{26}$.

${ }^{25}$ Estas reivindicaciones son importantes, pero hay que observar que no se habla en ningún momento de pluripartidismo, independencia del Pacto de Varsovia o salida del CAME. Se trataba de mejoras laborales, aunque se hable de forma general de representatividad del Parlamento, etc. No cuestionaba ningún punto de los considerados "sagrados" por la URSS. Despacho 207, 22 de octubre de 1956. AMAEX, R-4465-85.

${ }^{26}$ Despacho 668 de José María Aguirre, de 20 de noviembre de 1956. AMAEX, R-4465-86. 


\section{Valoración de los hechos}

Aguirre calificó lo ocurrido como el hecho de mayor trascendencia política en los países satélites después de la Segunda Guerra Mundial y tras la implantación del sistema comunista en la URSS. También señaló que él intuía una crisis o posible desacuerdo entre las autoridades polacas por el hecho de que el presidente Zirankiewicz estuvo en las honras fúnebres que se celebraron en honor de las fuerzas gubernamentales caídas en la represión de los rebeldes, pero no el primer secretario del Partido Comunista Polaco. Percibe como una muestra de debilidad el comunicado del presidente del Consejo, quien dijo que "después de los lamentables acontecimientos, Polonia proseguiria con su proceso de democratización", sin una reprobación fuerte de la actitud obrera, como era de esperar.

Más tarde, ya en octubre, el embajador muestra otra vez su extrañeza por la actitud blanda de los tribunales polacos para con los encausados de Poznan. De 154 encausados, sólo habían comparecido 26 y, por las sentencias tan benignas que se habian dado en el primer proceso, él informa de que en Poznan se preveía que el resto fueran sobreseídas ${ }^{27}$. En definitiva, se aprecia claramente que la versión de Aguirre es la de alguien que cree sinceramente que se ha producido una importante fractura en el bloque del Este y que la URSS ha tenido necesidad de pactar.

\subsection{Los escépticos}

José Sebastián de Erice, embajador de España en Austria: la necesidad polaca de pactar

Sus primeras noticias de las protestas obreras de junio proceden de los primeros días de julio en que recibe en Viena a un pequeño grupo de industriales que habian visitado recientemente la Feria de Muestras de Poznan y al embajador de Austria en Varsovia. Ellos se convierten en sus fuentes acerca de los conflictos que habían teniendo lugar en Polonia y, según esas informaciones acerca del comportamiento de la URSS con los países del bloque del Este, Erice atribuye las revueltas polacas ante todo a dos causas: la crisis económica que se estaba viviendo en el pais y la farsa soviética de la desestalinización.

La crisis económica estaba alcanzando límites serios de depauperación en el conjunto de los países satélites, aunque con efectos intensificados en Hungría y Polonia por existir en estos países una mayor resistencia antiestalinista. Erice sostiene que cuanto menor voluntad de incorporación se daba por parte de los ciudadanos de un país satélite al complejo soviético, la URSS respondía «matándolos

27 Despacho 563 de Antonio María Aguirre, 10 de octubre de 1956. AMAEX, R-4470-14. 
de hambre ${ }^{28}$. Los interventores rusos en cada país del bloque jugaban con las requisas, importaciones y exportaciones ya que, teóricamente, se lo permitía el sistema económico que los enlazaba, el CAME, y ello se habia convertido en un soterrado y durísimo modo de presión con los que eran poco colaboradores. No en vano, el lema que adoptaron los obreros de Poznan en la revuelta fue «pan y trabajo". No obstante, Erice señala también que el descontento era todavía más intenso en Hungría por «el hambre que se padece en el antiguo reino de S. Esteban ${ }^{29}$.

La farsa de la desestalinización fue otro de los motivos que se destacó como causante de la resistencia desde la embajada de España en Viena. El proceso había sido el siguiente. Todo el bloque del Este había sufrido una casi completa "bolchevización" desde 1948-1949, donde los más dóciles habían sido Checoslovaquia, Bulgaria, Rumania y Albania, y los más resistentes Hungria y Polonia, en el orden expuesto. El embajador Erice indicaba como prueba de las falsas medidas «liberalizadoras" la reconstrucción de alambradas ya deterioradas y las torretas vigiladas con ametralladoras que se estaban erigiendo nuevamente en la frontera húngaro-polaca, cuando se habían desmontado, con gran alarde informativo, sólo unas semanas atrás. Por otra parte, la visita de Jrushchov el 19 de octubre a Varsovia había logrado encontrar a un Gomulka conciliador y los ajustes de determinado personal en los puestos clave, aseguraban que no fuera posible un "segundo Budapest»: Gomulka quedaba como cabeza principal y visible, pero a su lado estaba Morawsky para evitar una «verdadera desviación del Estado Comunista» ${ }^{30}$.

En cualquier caso, cree en los deseos de independencia de Gomulka, aunque sabe que está frenado de antemano por la presión de la frontera occidental OderNeisse, por la cercanía a la frontera rusa desde la guerra - Varsovia está a $90 \mathrm{~km}$ de Rusia- y porque no se podían entender los acuerdos polaco-soviéticos que cerraron la crisis sin tener en cuenta lo que estaba ocurriendo en Hungría. Todo su texto expresa que no confía en que vaya a cambiar nada porque Polonia estaba demasiado presionada por el tema fronterizo. La URSS, aunque tuviera que ceder en algo, ganaría un aliado incondicional para el futuro porque estaban en juego sus límites espaciales: los territorios arrebatados a Alemania sólo los podía mantener Polonia con el apoyo de la URSS. Gomulka no quiso exponerse ni a perder territorio ni a una invasión como la soviética en Hungría y aceptó pactar; la URSS no deseaba dos conflictos simultáneos e hizo ciertas concesiones. Erice se detiene

${ }^{28}$ A diferencia del levantamiento de Alemania Oriental de 1955, que había tenido un carácter marcadamente político y xenófobo respecto a la URSS, en Poznan había sido la reacción primaria de un pueblo hambriento y de unos salarios de miseria que se habían tornado incapaces del más básico mantenimiento de las necesidades cotidianas.

${ }^{29}$ Despacho 232-2 de José Sebastián de Erice, 2 de julio de 1956. AMAEX, R-4470-14.

${ }^{30}$ El 18 de noviembre habían concluido las negociaciones de Gomulka con Bulganin y Jrushchov en Moscú y el mismo día pronunció una alocución por radio defendiendo la indestructible unión con Moscú para garantizar sus fronteras. 
especiaimente en dos puntos de estos pactos: los acuerdos sobre la permanencia en Polonia de las tropas soviéticas y la cuestión religiosa.

\section{Los acuerdos sobre la permanencia de tropas}

Por parte de la URSS, a pesar de que públicamente las negociaciones fueron llevadas por Bulganin y Jrushchov, entre bastidores estaba Zhúkov, lo que es indicativo de la presencia del sector duro en los acuerdos. Se basaron en 21 puntos que podemos resumir en los siguientes:

- Estacionamiento provisional de las tropas en Polonia sin poder inmiscuirse en asuntos domésticos polacos.

- Firma de «acuerdos especiales» para las siguientes cuestiones: número, calidad y lugar del estacionamiento de las tropas; condiciones de entrada y salida de Polonia de soldados, oficiales y familiares del ejército soviético, así como condiciones de sus residencias, cuarteles, etc.; normas de utilización de aeródromos e instalaciones militares del ejército polaco (aquí señaló Erice que se debía afinar mucho por parte de Polonia o sería lo que permita a los Soviets intervenir en el país); condiciones para la utilización de las vías polacas de comunicación. Es exclusiva de Polonia la elección del trazado y construcción de carreteras estratégicas sobre todo hacia la frontera OderNeisse; fiscalidad especial para las tropas asentadas, franquicia aduanera y cambios de moneda. La URSS pretendía que se abaratara la vida a los soldados rusos y que, en lugar de que se sometieran al cambio oficial de 4 zlotys por rublo, se les facilitara a 10 zlotys por rublo.

- Los movimientos de tropas soviéticas fuera de sus acantonamientos requerirán la conformidad polaca (según Erice, el mayor triunfo de Gomulka).

- Los edificios, aeródromos y servicios telefónicos o de vigilancia que debían ser construidos para uso de las tropas soviéticas, requerirán la aprobación polaca. Además, en un futuro, esas instalaciones serán entregadas a Polonia y con las indemnizaciones que se estipule (deben abonarse pagos por las expropiaciones o daños que produzca la estancia de las tropas en Polonia).

- Los miembros del ejército soviético y sus familiares habrán de ajustarse a la jurisdicción polaca, excepto cuando el delito sólo ataña a la URSS o perjudique únicamente a un miembro del ejército soviético o a un familiar suyo.

- Se debian nombrar dos plenipotenciarios, uno por cada país, para tratar con los gobiernos (Erice lo interpetó como un deseo de control de Zhújkov, que buscaba su propio delegado, independiente de Chepilov o Jrushchov y de la propia misión militar existente).

- Se otorgaba estatuto militar al elemento civil que trabajaba con las unidades militares (Erice se escandalizó y lo percibió como un deseo de incorporar a la 
policía política soviética que trabajaba en Polonia al estatuto preferencial del ejército).

En definitiva, el juicio de Erice es que el gran triunfo de Gomulka fue el reconocimiento de la soberanía polaca al poder intervenir en la cantidad, calidad y emplazamiento de las tropas soviéticas, reconociéndose la soberanía polaca. Pero la baza de la URSS fue la conformidad polaca sobre el uso de las instalaciones militares que le dejaban un amplio margen de actuación, incluso en asuntos exclusivamente privativos de Varsovia. Después dependeria de cómo se aplicarán los "acuerdos especiales", pero el acuerdo en sí ya era potencialmente peligroso.

Las tropas, pues, se quedaron con condiciones, pero se quedaron. Gomulka no consiguió su salida, que había sido, como en Hungría, una de las principales reivindicaciones de la ciudadanía. Erice afirma que los polacos eran "profundamente patriotas" $y$, por ello, fue un éxito que las tropas se tuvieran que quedar con condiciones, reconociendo la soberanía de Polonia y la prohibición de mezclarse en los asuntos internos del país. Pero se tuvo que aceptar su presencia en contra del sentir prácticamente unánime de los comunistas polacos.

\section{El acuerdo con la Iglesia}

En ese segundo tema es donde Erice cree que los polacos consiguieron un verdadero triunfo. Como la mayoría de la población era profundamente católica, Gomulka permitió una impresionante manifestación pública por el regreso a Varsovia del cardenal Stefan Wyszynski, detenido y encarcelado en 1950 sin juicio alguno, y se tomaron dos importantes medidas conciliadoras: la devolución parcial de los bienes incautados a la Iglesia y la introducción de la enseñanza religiosa en las escuelas siempre que lo solicitaran padres y tutores. En Roma, sin embargo, se calificó de "cambios ligeros" porque en el Vaticano se pensaba que el hecho de que los padres debieran solicitar la enseñanza religiosa podía entrañar peligros para ellos. En conclusión, se otorgaron una serie de concesiones por parte de la URSS que, en opinión de Erice, serían:

- Un acuerdo para que se quedaran las tropas soviéticas, no una imposición.

- Otro acuerdo de fronteras: Rusia se mantendria a $80 \mathrm{~km}$ de Varsovia y le garantizaría su frontera Oder-Neisse, pero, a cambio, Polonia se comprometía a oponerse a cualquier intento de unificación de Alemania, si Bonn no aceptaba reconocer a Alemania Oriental.

- Se retiró a Rokossowski, pero al firmar el acuerdo Rusia se ratificó en que las posiciones en Polonia serían las últimas que se abandonarían militarmente.

- Con la firma de acuerdos con Gomulka, Rusia le confirió una fuerza ante los comunistas polacos que le permitiría reformas más adelante. Con la aceptación de pactos estaba reconociendo lo difícil que era la permanencia en 
otros países sin acuerdos. La URSS demostraba estar dispuesta a hacer concesiones y a admitir que lo que había no era un conglomerado comunista sometido a Moscú, sino aliado con Moscú.

Todo lo anterior facilitaría algo la vida a los polacos, pero no ofrecía solución alguna a la enorme crisis económica. Las noticias que Erice recogía le hicieron sostener que el "comunismo es un rotundo fracaso económico porque sin el estímulo personal de la propiedad, el ahorro y la herencia, no producen ni el campesino, ni el obrero fabril ni el taxista" ${ }^{31}$. La producción decaía cada vez más y desaparecian los productos que no eran de estricto mantenimiento de la supervivencia ${ }^{32}$. $Y$ es en ese terreno, el económico, donde Erice creyó que Rusia podia presionar más a Polonia, vendiéndole el menor trigo posible, aunque Polonia podía responder también a esas presiones, ya que Rusia dependía para su suministro energético del carbón polaco.

En definitiva, el embajador no creyó que pudiera haber un cambio real porque los intereses políticos de Jrushchov y su entorno no necesitaban ninguna apertura en Polonia. Encontraba justificado que Rusia mantuviera una extrema prudencia con los asuntos de Alemania del Este para propiciar en todo lo posible un acercamiento a Alemania Federal, pero no le era necesario en Polonia o Hungría y no tenía motivos para ceder. El interés que podía tener en una «liberalización" en la RDA que propiciara el diálogo con Alemania Occidental - la única manera de plantear el tema del reconocimiento de Alemania del Este- no tenía parangón con ningún tema en el resto de los paises del bloque por lo que no se debia esperar una gran colaboración ${ }^{33}$.

Por otra parte, en su política interna, Jrushchov, con la estrategia de las «liberalizaciones» trataba de buscar un contrapunto al grupo militar encabezado por el mariscal Zhúkov, partidario de un fortalecimiento del bloque soviético, en un Kremlin que era un hervidero de posiciones encontradas ${ }^{34}$. Zhúkov, en un primer momento, habia ayudado a Jrushchov a ser primer secretario del PCUS y primer ministro, a lo que él correspondió nombrándole miembro del Presidium, pero después sería un elemento discordante por su consenvadurismo. De hecho, en 1957 se produciría el primer choque de relieve entre Jrushchov y sus rivales, que se saldó con

${ }^{31}$ Cuenta la anécdota de que los taxis en Varsovia abundan por las mañanas porque es necesario justificar que se han recorrido $50 \mathrm{Kms}$. para cobrar el sueldo. Pero, en cuanto los cumplen, empiezan a desaparecer y por la tarde no hay ninguno.

32 Pone el ejemplo de que, en el último verano, las varsovianas llevaban únicamente dos modelos de calzado, ambos de los años 1939 ó 1940.

33 Hay que recordar que este sería el principal escollo vivido por la URSS y del que no lograria tratar con Eisenhower hasta 1959, cuando Jrushchov fue invitado a Camp David, provocando el consiguiente recelo en De Gaulle y Adenauer.

34 Georgui Konstantínovich Zhúkov, nació en 1896 y, tras una floreciente carrera militar, en 1942. 1943 dirigió magistralmente la defensa de Stalingrado, siendo ascendido a mariscal en 1943. Fue quién firmó en Berlín el acta de capitulación de las fuerzas alemanas el 8 de mayo de 1945 y fue nombrado diputado en el Soviet Supremo en 1946. Stalin, por temor a su popularidad, to relegó en 1947 a Odessa, pero cuando aquel murió, Zhúkov empezó a ascender y llegó a miembro del Presidium del Comité Central del PCUS en 1956. Más tarde sería retirado por el propio Jrushchov. Murió en 1974. 
la depuración de algunos más como Malenkov, Molotov, Kaganóvich, Bulganin, Voroshílov, representantes de distintas facciones defensoras de agricultura o industria, industrias pesadas o ligeras, o el apostar por una verdadera desestalinización o por la preservación de la seguridad interna ${ }^{35}$.

De cualquier modo, es muy notable la diferencia de simpatía que Erice mostraba por Polonia con respecto a Hungría y no se nos oculta la razón última: su convicción acerca de la religiosidad del pueblo polaco. Dice él literalmente: «No podemos olvidar que ese desgraciado pueblo polaco, católico y patriota, aunque por una extraña y casi monstruosa paradoja, siga siendo en el terreno económico todavía comunista, mira a Occidente. Es por esencia occidental y piensa en la ayuda que pueda llegarles de Occidente y, probablemente pide a la Virgen Patrona de Czestochowa que ilumine a Occidente para que una representación personal y material de sus elevadísimos ideales les guíe y les ayude a terminar su proceso de independización, aunque dos o tres guarniciones soviéticas sigan garantizando a los territorios alemanes del Este, a lo que Rusia no renuncia porque es su mejor carta en las negociaciones con Washington ${ }^{36}$.

No obstante, ya en febrero de 1957, Erice se reafirmó en sus sospechas de la marcha atrás de Gomulka al comprobar que se habia destituido a Staszewski como primer secretario general, sustituyéndolo por Ladislav Matwin, hasta ahora redactor jefe del órgano oficial de prensa del Partido Comunista Polaco, Tribuna Ludu. Staszewski habia sido uno de los organizadores de las manifestaciones de octubre de 1956, que lograron la salida del poder de Ochab y la entrada de Gomulka, mientras que Matwin, desde su periódico, había atacado desde el principio las posiciones de Gomulka acusándolo de revisionismo por otorgar mayor libertad a la Iglesia católica, por permitir al campesinado mayor disponibilidad de sus productos agrícolas y por haber aceptado el establecimiento de pequeños comerciantes e industriales. Todas ellas eran medidas inhibidoras del rígido control que ejercian las empresas estatales sobre la economía polaca y todas fueron constantemente criticadas por la nueva dirección.

En opinión de Erice, esos cambios no eran debidos a que Gomulka se hubiera apartado de sus planteamientos iniciales, sino a que habia tenido que echar las culpas a alguien para poder continuar las reformas aunque fuera muy lentamente. Por otra parte, apunta Erice, el gran problema de Polonia seguía siendo la profunda crisis económica y Polonia esperaba de modo realista más ayuda de Norteamérica que de la URSS ${ }^{37}$.

35 Talbo Afias, C.: La Unión soviética, 1917-1990. Ed. Síntesis, Madrid, 1993, pp. 135-136.

36 Informe Confidencial de José Sebastián de Erice. Despacho 476 de 18 de diciembre de 1956. AMAEX, R-4465-86.

37 Despacho 97 de José de Erice, embajador de España en Viena, 14 de febrero de 1957. AMAEX, R-4547-16- 
Ernesto de Zulueta, embajador de España en Suecia: el temor a las represalias de la URSS

Un ejemplo de este sector sería Ernesto de Zulueta, que atribuyó certeramente el levantamiento tanto a la miseria en que vivia la población, como al golpeado sentimiento nacional. En las causas del levantamiento mencionadas coincide con José de Erice, pero a diferencia de él Zulueta otorga credibilidad a los rebeldes polacos. Aunque no espera que vaya a haber una verdadera o profunda transformación estando el ejército en manos del mariscal polaco aunque prorruso Rokossovski, si cree que la revuelta de los obreros - que fue posible por el nuevo espiritu y la reanudación de las relaciones de Moscú con Tito- podría obtener mejores frutos más tarde. En su opinión, desde la desestalinización, «la tierra ha temblado bajo los pies de los jefes comunistas y cada revuelta dará lugar a otras semejantes que podrían tener lugar en una evolución futura, cuando incluso, el recuerdo de lo sucedido en Poznan se hubiera borrado»38. Estas consideraciones, hechas en julio de 1957, se modificaron algo unos meses después, en diciembre, pasando de la confianza en un futuro cambio al temor por la rapidez con que aquel se iba produciendo. Tanto en los tribunales de justicia, como en los sindicatos, en la enseñanza o en la prensa la liberalización se producía, desde su punto de vista, a un ritmo acelerado y se preguntaba hasta dónde iba a poder Gomulka separarse de la URSS, e incluso del comunismo. Su posición era temorosa ante la reacción de la URSS, máxime cuando, no satisfecha con las veinte divisiones acuarteladas en Varsovia, había llegado a reforzar el ejército ruso en Alemania Oriental.

Toda la prensa sueca criticó la situación de miseria de la población polaca y la respuesta del Gobierno con carros de asalto frente a la población desarmada. Los socialistas advirtieron, pese a todo, de la necesidad de que los gobiernos occidentales fueran cautos porque una respuesta de extrema crítica de Occidente hacia el gobierno polaco podría dar lugar a un renacimiento del estalinismo, a la vuelta atrás de un pueblo que empezaba a expresarse ${ }^{39}$.

\section{Los embajadores de España en Washington, Italia, Francia y Perú: el temor al reforzamiento comunista}

José Maria de Areilza, embajador de España en Washington, desconfíaba de cualquier cambio de los comunistas y se remitia a una entrevista aparecida en el $U$. $S$. News \& World Report con el antiguo jefe del gobierno polaco, Mikolajczyk, a finales de octubre de 1956. El antiguo mandatario afirmaba en ese diario que sería un error de EEUU ayudar a Gomulka, pues con ello sólo reforzaría a los comunistas, tanto rusos como polacos. Lo que proponia Mikolajczyk era llevar el asunto a

${ }^{38}$ Despacho 474-2 de Emesto de Zulueta, embajador de España en Suecia, 2 de julio de 1956. AMAEX, R-4470-14. 
las Naciones Unidas y obligar a que se celebrebaran elecciones libres, "donde los rojos serían completamente derrotados " ${ }^{40}$.

Dos meses después, en diciembre, Areilza se mostraba muy preocupado por las noticias que le llegaban de Polonia. Se lamentaba de que la juventud y los obreros de las fábricas habian dado un giro a la situación, que se habia agravado, y había escapado por completo al control del Gobierno. También consideraba preocupantes las organizaciones estudiantiles, de las que sólo era oficial la Juventud Comunista que, en la práctica, ya no existía. En su lugar habían surgido otras ilegales y sumamente activas: el Consejo de la Juventud Revolucionaria, violentamente anticomunista, antirruso y antisemita; la Juventud Católica, la Juventud Socialista o la Juventud Polaca Nacional-Comunista. Todos estos grupos reprochaban al Gobierno su falta de firmeza con los rusos y discutían a diario con las autoridades universitarias, lo que era una muestra evidente de la debilidad de las autoridades y de la fuerza de esas organizaciones por muy ilegales que fueran.

En contrapartida - se congratulaba Areilza - al menos había crecido la popularidad del cardenal Wyszcinsky y su apoyo tácito al Gobierno lograba mantener un equilibrio. Se pensaba que sin él se hubiera revivido en Polonia otra revolución. Paralelamente, el prestigio de Gomulka había decaido rápidamente: era abucheado en la universidad y ya no aparecía en las resoluciones votadas en las fábricas; se le criticaba su retroceso general en todo y, especialmente, en estos momentos, en lo referente a las próximas elecciones. Frente a lo que Gomulka había prometido en 1948, cuando su ruptura con Stalin, después empezó a apoyar y a presentar candidatos prosoviéticos o con la aprobación del Kremlin, que eran odiados hasta en lugares que no habían sido problemáticos y hubieran sido estables con sus propios candidatos ${ }^{41}$.

Areilza sostiene que el temor de que estallara un conflicto de importancia era grande y los observadores temían que el ejército polaco se opusiera firmemente a los rusos. Si eso ocurría, las tropas soviéticas podían ser trasladadas a sólo 30 ó $40 \mathrm{~km}$ de Varsovia para rodearla y poder así atacar en minutos, si era necesario. Grandes unidades navales rusas con base en la costa báltica podrían perfectamente evitar una acción eventual de la marina polaca, de modo que podría producirse una explosión semejante a la de Hungría. Occidente debía prepararse para tomar una decisión en cualquier momento ${ }^{42}$.

En la misma línea, ya en enero de 1957, el embajador de España en Italia se hacía eco de una opinión singular de "un antiguo embajador de Polonia en Italia» - de quien no desvela el nombre- y decía que este personaje había sido un de-

39 Informaciones anexas a los despachos de Ernesto de Zulueta. AMAEX, R-4470-14.

40 Despacho 1.757 de José María de Areilza de 30 de octubre de 1956. AMAEX, R-4465-86.

41 Personas odiadas por el pueblo eran: la Presidenta de la Organización de la Juventud Polaca, Jaworska; el Presidente del “Comité para la Paz", el escritor Iwaszkiewic y el secretario del partido, Albrecht. Informe sin firma, adjunto a un despacho de Areilza de 21 de diciembre de 1956. AMAEX, R4465-86.

42 Ibidem. 
clarado anticomunista, hasta el extremo de que dimitió por no representar a un gobierno sovietizado. Según ese antiguo diplomático, quien de verdad estaba llevando adelante los cambios en Polonia era el cardenal Wyszinsky y no Gomulka, que era «de capacidad muy inferior». Él aseguraba que el cardenal había comprendido que en Polonia no era posible terminar tajantemente con la URSS y que había que buscar una via intermedia en que coexistieran catolicismo y comunismo, además de tratar de que, de ningún modo, pudiera darse una masacre como se había dado en Hungría. Así, en sus propias palabras, se estaba creando en Polonia un "comunismo rosa", que era lo más deseable, dadas las circunstancias. Se había conseguido que la Iglesia tuviera tal libertad propagandística que Wyszinsky pronunciaba hasta tres sermones diarios en diversas localidades polacas desplazándose en avión. Su informante tenía la convicción de que ese tránsito hacia la independencia de la URSS no tenía vuelta atrás, pero se lamentaba de que ese "comunismo rosa" era muy peligroso porque si se iban imponiendo formas políticas de un cierto comunismo moderado "ejercerán un gran poder de atracción sobre las masas y sobre muchos intelectuales europeos que viven en regímenes capitalistas "43. Pese a estas opiniones, el embajador informaba de que en Italia, entre los políticos de derechas y de centro no se aceptaba la posición de Wyszinsky y se mantenía una oposición frontal al comunismo e, incluso, habían difundido que el cardenal Wyszinsky no goza de gran favor en el Vaticano.

Otro análisis de interés es el que hace el embajador de España en Francia, José Rojas y Moreno, también en octubre ${ }^{44}$. Él sí creyó que se estaba produciendo una desestalinización, pero consideraba que era algo realmente perjudicial para el resto del mundo libre, pues, desde su punto de vista, la gente en Polonia quería a Gomulka sólo como un mal menor, pero sabian que no se iba a destruir con leves modificaciones el edificio de terror creado por Stalin. Sin embargo, temía que esos cambios fueran contraproducentes porque la existencia de esa alternativa de «mal menor» podía impedir una reacción verdaderamente eficaz contra el comunismo. Podía causar una respuesta conformista que retrasara la verdadera oposición. José Rojas se mostró convencido de que hubiera sido mucho más conveniente para Occidente que no se hubieran producido cambios o reformas en el socialismo porque se le podría perder el miedo a Rusia y eso no era en absoluto deseable. Especialmente temia que se pudiera llegar a aceptar, incluso, a los comunistas en los Frentes Populares de Europa Occidental por parte de los republicanos de izquierdas o hasta de los demócratas cristianos, lo que sería altamente perjudicial para el futuro de las democracias ${ }^{45}$.

${ }^{43}$ Opiniones de un «antiguo diplomático polaco» a través del embajador de España en Italia. Despacho 36 de 14 de enero de 1957. AMAEX, R-4547-16.

44 Es llamativo que en dia tan señalado por la manifestación húngara de la víspera, con resultado de muertes, no haya mención alguna de estos hechos. Probablemente fuera demasiado pronto, pues, de hecho, la primera reacción que conocemos de parte de la embajada de España en Paris sobre los hechos de Hungria procede del día 28 de octubre.

${ }_{45}$ Despacho 2.459 de José Rojas y Moreno, embajador de España en Francia, 24 de octubre de 1956. AMAEX, R-4470-14. 
Por último, desde Lima, el embajador Antonio Gullón, identificado con el diario más beligerante anticomunista, La Prensa, reprochaba a las Naciones Unidas su inoperancia al no haber dejado a Polonia otra solución que aceptar el «comunismo nacionalista» de Gomulka para no exponerse a la tragedia de Hungría. El embajador no creía compatible ser nacionalista y ser comunista y denunciaba que el pueblo polaco, al que calificaba de católico y vigorosamente anticomunista, se había visto obligado a aceptar la farsa de las elecciones que había impuesto Gomulka, pero no habia votado por él, sino contra la URSS. En su opinión, las reformas constituirían una etapa efímera que obligaría a Polonia a tomar partido, a decidir en un futuro próximo entre comunismo o nacionalismo ${ }^{46}$.

\subsection{Los optimistas}

El Duque Primo de Rivera, embajador de España en Londres: la fe en la alternativa del exilio

Con fe también en el cambio, se expresaba en octubre el Duque Primo de Rivera, embajador de España en Londres, al poco tiempo de haber tenido lugar el nombramiento de Gomulka sustituyendo en el politburó a Rokossowski. Según él, la noticia dominaba toda la prensa y se esperaba que los dirigentes soviéticos amenazaran seriamente si Polonia emprendía la vía de un comunismo independiente. La posición polaca parecía firme y todos los medios hablaban con entusiasmo de independizarse de Moscú ${ }^{47}$. Días después, el embajador envió a Martín Artajo una carta con carácter de "personal y muy reservada" para darle a conocer un informe del general Anders en el que se aseguraba que había habido participación del exilio británico en el levantamiento polaco. Anders no sólo le había entregado dicho informe, sino que le había hablado personalmente transmitiéndole en el mayor secreto que él concretamente, con ayuda británica, habia participado en la insurrección de Varsovia. Anders opinaba que Gomulka duraría poco por su formación muy elemental y porque el pueblo y el ejército polaco eran anticomunistas en un $90 \%$, por lo que la opción de Gomulka era sólo un primer paso.

En el informe Anders exponía que la organización de exiliados polacos en Londres, el Consejo Polaco de Unidad Nacional, había declarado que deseaba una Polonia libre e independiente y no «otra forma de comunismo" por lo que concretaban sus aspiraciones en una serie de puntos:

- Retirada de las tropas soviéticas de Polonia.

- Retirada de oficiales soviéticos de las fuerzas armadas polacas.

46 "Polonia en la encrucijada», en el diario de Lima La Prensa, 26 de enero de 1957. Despacho 131 de Antonio Gullón, embajador de España en Lima. AMAEX, R-4547-16.

${ }^{47}$ Despacho 934 del Duque Primo de Rivera, embajador de España en Londres, de 22 de octubre de 1956. AMAEX, R-4465-86. 
- Elecciones parlamentarias completamente libres, bajo supervisión internacional.

- Una Constitución democrática.

- Reconocimiento de la frontera occidental polaca en la línea Oder-Neisse por parte de Occidente para que Polonia se liberara de la dependencia de la URSS.

- Mantenimiento de las grandes empresas industriales mineras y de transportes como propiedad de la nación - si el pueblo polaco lo decidia- como todo lo que se habia hecho en la posguerra con el esfuerzo y sacrificio del pueblo.

- No se pretendía volver a las grandes propiedades de tierra, pero sí suprimir las odiadas colectivizaciones forzosas ${ }^{48}$.

Los exiliados perseguian un cambio realista, aunque ya era muy ambicioso esperar una democracia formal al estilo occidental. Sabían que no podían volver a la situación anterior a las reformas agrarias que terminaron con la concentración de la tierra porque la mayoría de la población no los hubiera apoyado. Tampoco podían aspirar a privatizar todo, incluso los grandes complejos industriales - no se lo plantearon ni siquiera los revolucionarios en Hungría- entre otras razones porque nadie podía contar con un capital como para poder adquirir esas empresas y, menos todavía, ponerlas en explotación ${ }^{49}$. Pero sí pretendian tener unas elecciones libres y una vuelta a la democracia, ya que estaban seguros de que si las elecciones se celebraban, no saldría ganador el partido comunista ${ }^{50}$.

El Duque Primo de Rivera adjuntaba a sus informes desde Washington un amplio abanico de noticias de prensa de Londres que coincidían casi al completo en creer firmemente que se estaba produciendo un verdadero cambio en Polonia. Algunos como el Daily Telegraph o del Manchester Guardian de 21 de octubre de 1956 se congratularon sobre todo de la menor influencia que parecía que iba a ejercer en adelante la URSS y opinaban que el futuro de los movimientos comunistas estaba en el «titoísmo», otra forma de revolución social, pero independiente de Rusia ${ }^{51}$. Otros, aunque también interpretaban que era una disensión clara de la URSS, no creían que el propio Tito fuera a apoyar jamás la idea de que el Partido Comunista fuera únicamente partido hegemónico, sino que tendría que gobernar, por lo que no era una verdadera revolución porque no era un camino hacia

48 Dice el texto en este punto: «Hemos elegido permanecer en el exilio para trabajar por la libertad para Polonia, no para restaurar antiguas desigualdades y privilegios». Informe del General Anders adjunto al despacho 963 del Duque Primo de Rivera, embajador de España en Londres, de 26 de octubre de 1956. AMAEX, R-4466-9.

49 En Hungría se dio una situación similar en lo referente a no plantearse siquiera la desaparición de los grandes complejos estatales. Ver Ferrero Blanco, M. D., ob. cit., pp. 96-98.

50 Informe del General Anders adjunto al despacho 963 del Duque Primo de Rivera, embajador de España en Londres, de 26 de octubre de 1956. AMAEX, R-4466-9.

51 Textos adjuntos a despachos del Duque Primo de Rivera. AMAEX, R-4465-86. 
el pluripartidismo ${ }^{52}$. Finalmente, como contrapunto, The Times opinaba que sería absurdo suponer que los nuevos dirigentes polacos deseaban una auténtica ruptura con Rusia ya que eran «tan comunistas como polacos»53.

\section{Miguel de Aldasoro, embajador de España en Noruega: la evidencia de la crisis del sistema comunista}

Pese a que el sector más conservador del gobierno polaco culpó al «imperialismo" de las protestas de Poznan -como era habitual en cualquier caso de discrepancia- y los políticos, como en 1953 en Alemania del Este, se pusieron de parte de los tanques y las ametralladoras en contra del pueblo, el contraste de opiniones aparecido en la prensa noruega, aunque diferente según su procedencia, fue una demostración del rechazo al sistema vigente.

La prensa comunista, al igual que el sector no reformista del gobierno polaco, atribuyó a «los fascistas y al imperialismo» el inicio de la protesta y consideró que las manifestaciones no habían sido más que «una farsa que ha derramado sangre ajena comprada con dólares a la reacción y al fascismo" ${ }^{54}$. Desde una concepción muy diferente, la prensa socialista puso el acento en la dificultad añadida en que se encontraban los gobiernos de los países satélites comparados con la propia URSS. Dependian del apoyo de Moscú para mantener su dictadura, pero Jrushchov con sus declaraciones les había obligado a seguir una línea «liberalizadora" que provocaba una peligrosa relajación interior. Los gobiernos de los países de Europa Central veían a sus dirigentes como representantes de un poder extranjero, por lo que las reacciones de sus disidentes eran mucho más fuertes que las potenciales reacciones rusas.

Se enfrentaban además a problemas muy superiores a los de los rusos porque algunos, como Checoslovaquia o Polonia, habían tenido previas experiencias democráticas y la imposición del modelo soviético provocaba un rechazo que no se dio en Rusia. El embajador hacia suyas las palabras del diario, que terminaba diciendo: «los obreros de Poznan han sido aplastados, pero los efectos de la revuelta no podrán serlo y se darán en otros países, en la propia Rusia y hasta en el Norte de África 'donde ahora los comunistas presumen de defensores de los árabes' „55. Días

52 Opinión del News Chronicle de 22 de octubre de 1956. Adjuntado a despachos del Duque Primo de Rivera. AMAEX, R-4465-86.

${ }_{53}$ The Times, 21 de octubre de 1956. Adjuntado a despachos del Duque Primo de Rivera. AMAEX, R-4465-86.

54 Esa respuesta e interpretación de los órganos comunistas de culpar al capitalismo, imperialismo, fascismo, etc., de cualquier desacuerdo, disensión o rechazo del pueblo hacia sus acciones es un lugar común conocido sobradamente en cualquier país del bloque del Este hasta el cambio y crisis que se produce en los partidos comunistas occidentales tras la invasión de Checosiovaquia de 1968. Friheten, 1 de julio de 1956. Adjuntado a despachos de Miguel de Aldasoro. AMAEX, R-4470-14.

${ }_{55}$ Se trata de una alusión al gobierno de Nasser por su ayuda a los pueblos limítrofes en sus luchas independentistas. Arbeiderbladet, 4 de julio de 1956. Adjuntado a despachos de Miguel de Aldasoro, embajador de España en Noruega. 
después, ese mismo diario animaba a todos los países del mundo libre a seguir con sus protestas por lo ocurrido en Poznan e informaba de que el presidente de la Juventud Socialista Noruega, Reider Hirsti, había rechazado toda colaboración con los comunistas $^{56}$.

La prensa conservadora, contrariamente, interpretó lo ocurrido como una muestra de que las pequeñas mejoras del régimen no eran más que maniobras tácticas; que si el gobiemo polaco se habia jactado de liberar a 100.000 prisioneros políticos, no era suficiente y todavía tendrían que hacer mucho más para que el pueblo se sintiera libre. A esa opinión contribuyó en gran medida que las reivindicaciones no se limitaran a demandar libertad, sino "pan para comer", lo que era una demostración para nuestro embajador del fracaso del comunismo como sistema económico 57 .

Los liberales de izquierda criticaron fuertemente la represión y denunciaron que aviones a reacción, tanques pesados y ametralladoras de dos divisiones de infantería habían aplastado a las masas obreras en Poznan. Mantuvieron una rotunda oposición a los argumentos del Gobierno y afirmaron que los obreros, desesperados, habian asaltado el almacén Stalin, se habían apoderado de fusiles de la policia y habían tomado el centro de la ciudad coreando sus demandas, mientras el Gobierno respondía disparando contra todos. Según su testimonio, no se conocía aún cuántos habian muerto en las calles, ni cuántos habían sido fusilados en las cárceles ${ }^{58}$.

Finalmente, otras informaciones llegaban a precisar que los obreros de Poznan sabían que su trabajo beneficiaba en un tercio a Rusia, en otro tercio al gobierno polaco y que sólo el último tercio revertía en el pueblo, en sus conciudadanos. Por eso miles de ello abandonaron las fábricas e invadieron el centro de la ciudad en columnas espesas gritando «ipan!, jlibertad! y jfuera los rusos!»59.

\section{LAS CONSECUENCIAS INMEDIATAS DEL LEVANTAMIENTO}

En los meses finales de 1956, en noviembre y diciembre, cierta prensa polaca de diferentes sectores, empezó a tratar tres cuestiones reflejo de su aspiración: un régimen político esencialmente nacional. Esas cuestiones eran:

- La conveniencia del establecimiento de relaciones diplomáticas con Bonn.

- El acuerdo firmado entre la Iglesia católica y el nuevo gobierno polaco.

- La celebración de elecciones parlamentarias para el próximo enero.

56 Arbeiderbladet, 7 de julio de 1956. AMAEX, R-4470-14.

57 Morgenbladet, 2 de julio de 1956. Adjuntado a despachos de Miguel de Aldasoro. AMAEX, R-4470-14.

58 Dagbladet, 29 de julio de 1956. Adjuntado a despachos de Miguel de Aldasoro. AMAEX, R-4470-14.

59 Diario Noruego de Comercio y Navegación, de filiación «independiente». 4 de julio de 1956. Adjuntado a despachos de Miguel de Aldasoro. AMAEX, R-4470-14. 
El establecimiento de relaciones diplomáticas con Alemania Federal provocó de inmediato la reacción de la prensa de Alemania del Este, que inmediatamente recordó a los polacos la invasión alemana de Varsovia, imputando toda la responsabilidad de los sufrimientos polacos durante la guerra a la Alemania Federal, sin mencionar siquiera la contribución de la URSS. El acuerdo con la Iglesia, resultado evidente de la política de atracción del régimen polaco hacia los católicos, que en Polonia eran muchos y constituían una importante baza de apoyo al Gobierno, quedó en los siguientes términos:

- Polonia podría proveer en el futuro las sedes vacantes.

- Se autorizaba la enseñanza religiosa en las escuelas a petición de los padres.

- Se decretaba la libertad de todos los religiosos detenidos.

- Se restablecía el culto en cárceles y hospitales.

- Se aceptaba la designación de cinco obispos para la zona Oder-Neisse ${ }^{60}$.

En mayo de 1956, había aparecido en The Times una noticia referente a las manifestaciones de un representante de la Cámara Alta británica al tratar de los problemas y dificultades con que tropezaba la libre difusión de la Biblia y otros libros sagrados en ciertos países. Lord Stansgate anunció que «desde que el Vaticano ha perdido el control sobre Polonia, la British and Foreing Bible Society ha enviado a Polonia 1.020 .000 ejemplares de las Sagradas Escrituras"61.

Respecto al tema de las elecciones, Gomulka se apresuró a declarar que los "partidos burgueses" no podrían participar en las elecciones. Las listas serían únicas, con varios candidatos para cada puesto, entre los que podría elegir el votante. La novedad estaba en que, al parecer, los sindicatos y las agrupaciones universitarias se habian puesto de acuerdo en designar ellos a quienes figuraran en las listas, para que, aunque tuvieran que ser comunistas, al menos fueran "patriotas" 62.

Seis meses después del levantamiento de octubre, los logros conseguidos por el gobierno de Gomulka eran tan notables comparados con la situación prece-

${ }^{60}$ Este fue un asunto sumamente conflictivo: el Vaticano procedió a reorganizar las diócesis situadas al Este de la línea Oder-Neisse, en antiguos territorios alemanes que quedaron después de la guerra bajo administración polaca. Los cinco obispos nuevos que se nombraban quedaban bajo las órdenes directas del Cardenal Primado de Polonia, Msgr. Wyszynski, debido a sus buenos oficios ante el gobierno polaco. La prensa alemana reaccionó con estupor y se apresuró a aclarar que, según informes del propio Vaticano, la medida no significa su reconocimiento de la línea Oder-Naisse como frontera definitiva. Despacho 709-1 de Antonio Maria de Aguirre de 5 de diciembre de 1956. AMAEX, R-4397-23.

${ }_{61}$ Es de suponer que se tratara de una Biblia anglicana. Que el Vaticano hubiera perdido el control sobre Polonia era una forma de criticar los acuerdos a los que habian llegado los obispos polacos con las autoridades del país para lograr un "modus vivendi» aceptable. Despacho 183 del Director General de Política Exterior de Madrid al embajador de España en la _Santa Sede. AMAEX, R-4398-114.

62 Era el nombre con el que se indicaba a los partidarios del "comunismo nacional", "comunistas polacos", independientes de la URSS. Despacho 727 de Antonio María Aguirre, de 12 de diciembre de 1956. AMAEX, R-4452-45. 
dente, que los polacos podían felicitarse de sus acuerdos con la URSS y de haber evitado una tragedia como la húngara, aunque ya habian dado comienzo las contradicciones por las que los seis meses habían sido agitados política y socialmente. Más tarde se retrocederia claramente, aunque ni siquiera esos logros hubieran sido posibles sin el durísimo desenlace húngaro. Fue evidente que los procesos de ambos levantamientos habían estado profundamente ligados. Los cambios principales en Polonia, en los primeros tiempos, fueron los siguientes:

- Sobre la colectivización forzosa, en Polonia se obtuvo uno de los mayores logros. En cuanto los campesinos oyeron a Gomulka criticar ese sistema y sus pobres rendimientos, empezaron a disolver kolkhozes y a repartirse tierras y ganados. De las 10.000 cooperativas que habian existido, a los seis meses quedaba menos de la cuarta parte.

- En la industria, se volvieron a aceptar los sindicatos en los términos de antes de la guerra, con un rechazo del modelo soviético, aunque se reconoce al Partido la dirección ideológica y política, pero se suprimían todas las formas de intervención del Partido en los sindicatos.

- En diversos temas culturales, como prensa, escuela y asociaciones juveniles, la prensa atacaba duramente todo lo relacionado con el estalinismo; la escuela volvió a impartir clases de religión en aquellos centros en que los padres lo reclamaran, tanto en primaria como en secundaria; en las asociaciones juveniles, a la vez que se disolvia la antigua Juventud Polaca Comunista, surgieron otras nuevas como Juventud Socialista, Juventud Democrática, Juventud Rural, Juventud Revolucionaria y una Nueva Asociación Comunista.

- En las relaciones con la URSS, Polonia obtuvo teóricamente una indemnización por las pérdidas financieras sufridas entre 1945 y 1953 como consecuencia de la exportación de carbón polaco a la URSS a precios ridículos. Para Polonia había supuesto una pérdida de 2.100 millones de rublos, pero las indemnizaciones se anularon finalmente como compensación de otras deudas contraídas por Polonia frente a la URSS. Lo único que recibió la delegación polaca de la URSS fue un empréstito de 700 millones de rublos reembolsables de 1963 a 1965 y 1.400 .000 toneladas de cereales por valor de otros 400 millones de rublos.

- En la defensa y fuerzas del orden, los polacos pudieron eliminar a los rusos del ejército, de la policía y de la industria, donde estaban como "especialistas». El dato más significativo y simbólico se dio en el ejército con la marcha del mariscal Rokossowski en noviembre y de treinta generales más. La policía, por su parte, también tuvo el importante cambio al desaparecer como organismo autónomo y quedar debajo del Ministerio del Interior.

- En la magistratura fueron expulsados un buen número de procuradores y jueces que habian ejercido pese a estar desprovistos de formación juridica y fueron reintegrados en sus puestos funcionarios destituidos durante el estalinismo. 
- En la administración se empezó a licenciar empleados, llegando hasta 40.000 , aunque todavía se consideró muy insuficiente.

- En la Iglesia, la liberación y las nuevas atenciones dispensadas al cardenal primado Stefan Wyszynski dieron lugar a que se pronunciara la conocida e irónica frase: «Polonia está gobernada por el Cardenal Gomulka y por el Primer Secretario Stefan Wyszynski». Esa frase era consecuencia de los logros de la Iglesia frente al Estado: el Gobierno había aceptado derogar el decreto de 1955 que le había dado derecho a intervenir en el nombramiento de las autoridades eclesiásticas de diferentes jerarquías; había autorizado llevar el auxilio de la religión a hospitales y cárceles y permitió el regreso al país de las órdenes religiosas femeninas y de los sacerdotes expulsados anteriormente de los departamentos occidentales.

- Los salarios, que desde comienzos de 1957 se habían aumentado en un $12 \%$ de media, llegaron a un $25 \%$ en el caso de los mineros. A la par, fue inevitable una subida de precios también, de un 1 y $1 / 2 \%$ los alimenticios y de un $2 \%$ los industriales.

- La gran subida de salarios de los mineros fue debida a que constituían el sector más preocupante del mundo laboral. Las cotas esperadas en la producción de carbón no se podían cumplir por no haber podido modernizar la maquinaria y por falta de mano de obra. Los obreros abandonaban las minas por las míseras condiciones de las viviendas y de la infraestructura en general: sólo en 1955 habian abandonado las minas 70.000 obreros. Se habia intentado cubrir ese déficit con los trabajos forzados de presos y soldados, que habían alcanzado el $18 \%$ de la plantilla en 1953, como consecuencia de un convenio de posguerra entre Rusia y Polonia, en virtud del cual Polonia se vio obligada con la URSS desde 1946 a 1953, lo que ocasionó a Polonia unas pérdidas de unos $2 \frac{1}{2}$ millones de rublos. En 1956 los presos ya no llegaban al $2 \%$ ni los soldados el $7 \%$.

- Otras industrias, como la fábrica de automóviles de Lublin, que debia producir anualmente 12.000 camiones, no había pasado de 3.000 en 1956 e igual ocurría en el sector de turismos y de tractores.

- Políticamente, sin embargo, las concesiones al Kremlin empezaron desde los primeros meses: sus presiones, las de los países del entorno y las de algún partido comunista occidental como el francés, hicieron comprender a Gomulka que no tendría apoyos en sus objetivos de cambio y que quedaría aislado. A esto se añadía que, desde marzo de 1957, con el ascenso en la URSS de Gromyko, se recrudeció la línea dura y aumentó la influencia soviética sobre Polonia. Prueba de ello fue la visita de Rapacky, jefe de Negocios Extranjeros polaco, a Gromyko para "rendirle pleitesía" y asegurarse así el apoyo para la frontera Oder-Neisse, ya que desde la guerra parte de las tierras más ricas de Polonia pasaron a pertenecer a Bielorrusia. 
También se hizo patente la nueva tendencia en el nombramiento de nuevos cargos: se había sacrificado ya a Staszewsky sustituyéndolo por Matwin, redactor del Tribuna Ludu y crítico implacable de Gomulka. En consecuencia, desde la apertura del Parlamento se impuso un Consejo de Estado que podría gobernar por decreto y el mismo Gomulka nombró para la segunda vicepresidencia a Zenón Nowak, uno de los jefes del grupo Natolin, pese a la oposición de un buen número de diputados ${ }^{63}$. Nowak era considerado uno de los «ojos de Moscú» junto a Cyrankiewicz, también incorporado. Otro nuevo cargo fue Casimiro Misal, en la dirección del Banco de Reconstrucción e Inversiones - la palanca de mayor influencia sobre las masas campesinas-considerado uno de los mayores teóricos de la economía rígida comunista y absolutamente opuesto a Gomulka ${ }^{64}$. Se fue dando la sustitución de "gomulkistas" por "natolistas" hasta el extremo de que empezó a aparecer cada vez con mayor frecuencia en la prensa - que, aún denominándose oficial, estaba dirigida por Ochab y los "natolistas»- una auténtica campaña de críticas crecientes a la apertura de Gomulka con afirmaciones acerca de la necesidad de terminar con "esos resabios burgueses" 65 .

En opinión de Erice esta campaña se debía a nuevas presiones del embajador soviético en Polonia desde la subida al poder de Gromyko y criticó la falta de ayuda de Occidente, recordando las veces que Polonia se había arriesgado en la historia y no la habían correspondido. Hace un amargo comentario respecto a que "ya se vio lo que Occidente 'ayudó' en Hungría, por lo que Polonia no podía esperar nada mientras no cambiaran EEUU, la OTAN y la ONU"66. Ciertamente, la situación polaca era delicadísima: por un lado tenía que estar a bien con la URSS por todas las razones esgrimidas; por otro, necesitaba urgentemente el apoyo económico de EEUU, por lo que tampoco podía descuidar la esperada «apertura». Con ese objetivo económico, Gomulka envió una misión a EE.UU para solicitar préstamos, salir de su crisis e ir asegurando su emancipación de la URSS.

Se hacia lo que se podía, dada la situación: se había devaluado el zloty desde 4 zlotys por dólar hasta 24 zlotys por dólar. Una depreciación de 1 a 6 , con vistas a la negociación con Washington, aunque teniendo en cuenta que el comercio era absolutamente estatal y que se hacía por el sistema de Arreglos de Pagos o de Acuerdos Bilaterales, era realmente lo mismo que el zloty valiera 4 que 24. En donde sí hubiera podido influir era en el turismo, si hubiera habido. $Y$ tampoco tenía efecto en el complejo del CAME puesto que su relación frente al rublo no se de-

63 Informe de la Dirección de Asuntos Políticos de Europa Oriental, del Ministerio de Asuntos Exteriores español. Despacho 258. AMAEX, R-4531-39.

64 Despacho n. 191 de marzo de 1957 de José de Erice. AMAEX, R-4531-39.

65 Medios de comunicación como la radio o la prensa empezaron a acosar con fuerza: el diario Sztandar Mlodych, el semanario Po Prostu, el semanario Przeglad Kulturkamy, o el universitario Nowa Kultura.

66 Despacho n. 304 de julio de 1957 de José de Erice. AMAEX, R-4531-39. Igualmente opinaba el embajador de Copenhague Merry del Val, que se expresó en términos muy similares respecto a la necesidad del cambio de actitud de EE.UU. si pretendian que triunfaran las reformas polacas. AMAEX, R4531-39. 
valuó. En definitiva, la situación de caos económico no encontró salida entre las presiones soviéticas y la reticencia a ayudar de EEUU: con una crisis económica tan palpable y que había sido la mayor causa del alzamiento político, Polonia había tenido grandes esperanzas en la ayuda de EEUU, pero, finalmente, sólo conseguiría unos 100 millones de dólares de los 300 que le había solicitado ${ }^{67}$.

En octubre de 1957, al año del nombramiento de Gomulka, éste denunciaba la existencia de "grupos oscuros" dentro del partido refiriéndose a los más críticos con él y les acusaba el «revisionismo". Todo indica que había comprendido que no tendría apoyos exteriores y que sabía cuáles eran los límites que le imponía la URSS.

España no tuvo ninguna participación directa en la crisis polaca, pero sí fue tanteada desde fuera respecto a si apoyaría y reconocería un golpe de estado en Polonia contra Gomulka. En octubre de 1958 había llegado a España el plenipotenciario Kniaziolucki, representante del gobierno del presidente Zalewski -el continuador de los primeros exilados en Londres- y que estaba en la oposición del general Anders. Kniaziolucki consideraba a Anders "vendido" a los americanos y le acusaba de que aquellos le habían entregado 1.200.000 dólares para espiar en Polonia, de los que 600.000 se debían utilizar en el envío de alimentos durante la crisis y el resto para las labores de espionaje. Ninguna de esas cantidades cumplió su destino, pero para dar a los americanos sensación de eficacia se había llegado a detener y fusilar a muchos polacos, motivo por el cual el general Anders quedó completamente desacreditado.

El objetivo de la visita a España se limitaba a informar de que el gobierno Zalewski estaría dispuesto a reconocer a los que se alzaran en Polonia tras una revuelta armada o golpe de Estado "del tipo Irak» para echar del poder a Gomulka, cada vez más cuestionado y, por su condición de judío, hasta responsable de un creciente antisemitismo que antes no existía entre la población. Estos exilados pedían a España que les proporcionara "ayuda moral», como se lo habían pedido al gobierno turco y al persa, "que eran fiables por ser profundamente anticomunistas", mientras que no confiarían más en franceses, ingleses y americanos, "que siempre les dejaban en la estacada" ${ }^{68}$. No hay noticias de que dicho golpe se llegara a intentar, pero es una evidente muestra de que en sólo dos años Gomulka había terminado con las esperanzas de cambio.

\section{BIBLIOGRAFÍA}

Acosta, D.: "Prólogo" en MORENo, N.: Escritos sobre revolución politica, pp. 2-3. http://www.geocities.com/obreros.geo/ Edición electrónica. Diciembre, 2001.

Cabrera, M.; Juliá, S y Martín Aceña, P.: Europa, 1945-1990. Ed. Pablo Iglesias, 1992.

${ }^{67}$ Despacho n. 191 de marzo de 1957 de José de Erice. AMAEX, R-4531-39.

68. Despacho 592. AMAEX, R-5931-13. 
DEUTCHER, 1.: “La tragedia del partido comunista polaco», en El marxismo de nuestro tiempo. Ed. Era. México, 1975.

HeLMREICH, E.C.: "Spring in October. The Polish Revolution, 1956", en Political Science. American Academy of political and society. New York, 1958.

Gutierrez Álvarez, J.: “Reforma en Polonia, revolución en Hungría». Historia y Vida, vol. 19, pp. $42-54$. Madrid, 1986.

Mazower, M.: La Europa Negra, p. 160, citado por DuARte, A. en MARTín de la Guardia, R. y PÉrez SÁnCHEZ, G. (coord.): La Europa del Este. Del Telón de Acero a la integración en la Unión Europea. Biblioteca Nueva, Madrid, 2002 , p. 45.

MaRtín DE LA GuaRdia, R.: «El movimiento europeo frente a la división del continente: la Conferencia sobre Europa Central y Oriental», en Martín De La Guardia, R. y Pérez Sánchez, G. (coords.): La Europa del Este. Del Telón de Acero a la integración en la Unión Europea. Biblioteca Nueva, Madrid, 2002, pp. 47-62.

MIRANDA, N.: “Sobre la convocatoria al XXII Congreso del PC», en Clase contra clase. Fracción trotskysta Estrategia Internacional. http://www.clasecontraclase.cl/extras/pol2.html. 12-7-2002, p. 2.

MORENO, N.: Revoluciones del siglo $X X$, en Cuadernos de Formación. Buenos Aires, 1986.

MORENO, N.: Escritos sobre revolución política. http://www.geocities.com/obreros.geo/ Edición electrónica. Diciembre, 2001.

Pongrátz, G.: Corvin circle, 1956. Ed. Szivárany, Chicago, 1983, p. 14.

FERRERO BLANCO, M. D.: La revolución húngara de 1956. El despertar democrático de Europa del Este. Coedición Universidad de Huelva-Embajada de la República de Hungría en España-Instituto siglo XXsiglo XXI de Budapest. Universidad de Huelva, 2002.

HÉlLer, A. y FEHER, F.: De Yalta a la «Glasnost». Pablo Iglesias, Madrid, 1992. pp. 124-137.

Patula, J.: Europa del Este: del estalinismo a la democracia. Siglo XXI. México, 1993.

Talbo ARIAS, C.: La Unión soviética, 1917-1990. Síntesis, Madrid, 1993, pp. 135-136.

Veiga, F., Da CAL, E. y DuARte, A.: La paz simulada (1941-1991). Alianza Editorial, Madrid, 1998.

WINIWCKI, J.: Las distorsiones de las economias de tipo soviético. Alianza Editorial, Madrid, 1966.

Zorgbibe, Ch.: Le monde depuis 1945. Ed. Presses Universitaires de France. Paris, 1989.

\section{FUENTES}

Informe de Fulgencio Vidal y Saura, embajador de España en Finlandia. AMAEX, R-4452-45.

Carta Pastoral Polaca. Despacho 19 de 16 de enero de 1956 de Fernando Maria Castiella. AMAEX, R4452-13.

Despacho 81 de 1 de marzo de 1956 de Fernando María de Castiella. AMAEX, R-4452-13.

Despacho 176 de Fulgencio Vidal y Saura, Encargado de Negocios de España en Finlandia, de 2 de julio de 1956. AMAEX, R-4470-14.

Despacho 730 de Ramón Sedó Gómez, Encargado de Negocios de España en Berna, de 3 de julio de 1956. AMAEX, R-4470-14.

Despacho 618 de 26 de octubre de 1956. AMAEX, R-4465-86.

Despacho 381 de Antonio María de Aguirre de 6 de julio de 1956. AMAEX, R-4465-85.

Despacho 609 de Antonio María Aguirre de 24 de octubre de 1956. AMAEX, R-4465-85.

Despacho 207, 22 de octubre de 1956. AMAEX, R-4465-85.

Despacho 668 de José María Aguirre, de 20 de noviembre de 1956. AMAEX, R-4465-86.

Despacho 563 de Antonio Maria Aguirre, 10 de octubre de 1956. AMAEX, R-4470-14.

Despacho 232-2 de José Sebastián de Erice, 2 de julio de 1956. AMAEX, R-4470-14.

Informe Confidencial de José Sebastián de Erice. Despacho 476 de 18 de diciembre de 1956. AMAEX, R-4465-86.

Despacho 97 de José de Erice, embajador de España en Viena, 14 de febrero de 1957. AMAEX, R-454716-

Despacho 474-2 de Ernesto de Zulueta, embajador de España en Suecia, 2 de julio de 1956. AMAEX, R4470-14.

Informes anexos a los despachos de Ernesto de Zulueta. AMAEX, R-4470-14.

Despacho 1.757 de José María de Areilza de 30 de octubre de 1956. AMAEX, R-4465-86.

Informe sin firma, adjunto a un despacho de Areilza de 21 de diciembre de 1956. AMAEX, R-4465-86.

Opiniones de un «antiguo diplomático polaco" a través del embajador de España en Italia. Despacho 36 de 14 de enero de 1957. AMAEX, R-4547-16.

Despacho 2.459 de José Rojas y Moreno, embajador de España en Francia, 24 de octubre de 1956. AMAEX, R-4470-14. 
Despacho 131 de Antonio Gullón, embajador de España en Lima. AMAEX, R-4547-16.

Despacho 934 del Duque Primo de Rivera, embajador de España en Londres, de 22 de octubre de 1956. AMAEX, R-4465-86.

Informe del general Anders adjunto al despacho 963 del Duque Primo de Rivera, embajador de España en Londres, de 26 de octubre de 1956. AMAEX, R-4466-9.

Textos adjuntos a despachos del Duque Primo de Rivera. AMAEX, R-4465-86.

Textos adjuntos a despachos de Miguel de Aldasoro. AMAEX, R-4470-14.

Arbeiderbladet, 4 de julio de 1956. Adjuntado a despachos de Miguel de Aldasoro, embajador de España en Noruega. AMAEX, R-4470-14.

Arbeiderbladet, 7 de julio de 1956. AMAEX, R-4470-14.

Morgenbladet, 2 de julio de 1956. Adjuntado a despachos de Miguel de Aldasoro. AMAEX, R-4470-14.

Dagbladet, 29 de julio de 1956. Adjuntado a despachos de Miguel de Aldasoro. AMAEX, R-4470-14.

Diario Noruego de Comercio y Navegación, de filiación aindependiente». 4 de julio de 1956. Adjuntado a despachos de Miguel de Aldasoro. AMAEX, R-4470-14.

Despacho 709-1 de Antonio Maria de Aguirre de 5 de diciembre de 1956. AMAEX, R-4397-23.

Despacho 183 del director general de Política Exterior de Madrid al embajador de España en la Santa Sede. AMAEX, R-4398-114.

Despacho 727 de Antonio Maria Aguirre, de 12 de diciembre de 1956. AMAEX, R-4452-45.

Informe de la Dirección de Asuntos Políticos de Europa Oriental, del Ministerio de Asuntos Exteriores español. Despacho 258. AMAEX, R-4531-39.

Despacho n. ${ }^{\circ} 191$ de marzo de 1957 de José de Erice. AMAEX, R-4531-39.

Diario Sztandar Mlodych, semanario Po Prostu, semanario Przeglad Kulturkarny y diario universitario Nowa Kultura. Adjuntado a despachos de Miguel de Aldasoro. AMAEX, R-4470-14.

Despacho n. ${ }^{\circ} 304$ de julio de 1957 de José de Erice. AMAEX, R-4531-39. Igualmente opinaba el embajador de Copenhague, Merry del Val, que se expresó en términos muy similares respecto a la necesidad del cambio de actitud de EEUU si pretendian que triunfaran las reformas polacas. AMAEX, R4531-39.

Despacho n. ${ }^{\circ} 191$ de marzo de 1957 de José de Erice. AMAEX, R-4531-39.

Despacho 592. AMAEX, R-5931-13. 